\title{
Human Pegivirus in Patients with Encephalitis of Unclear Etiology, Poland
}

\author{
Iwona Bukowska-Ośko, Karol Perlejewski, Agnieszka Pawełczyk, Małgorzata Rydzanicz, \\ Agnieszka Pollak, Marta Popiel, Kamila Caraballo Cortés, Marcin Paciorek, Andrzej Horban, \\ Tomasz Dzieciątkowski, Marek Radkowski, Tomasz Laskus
}

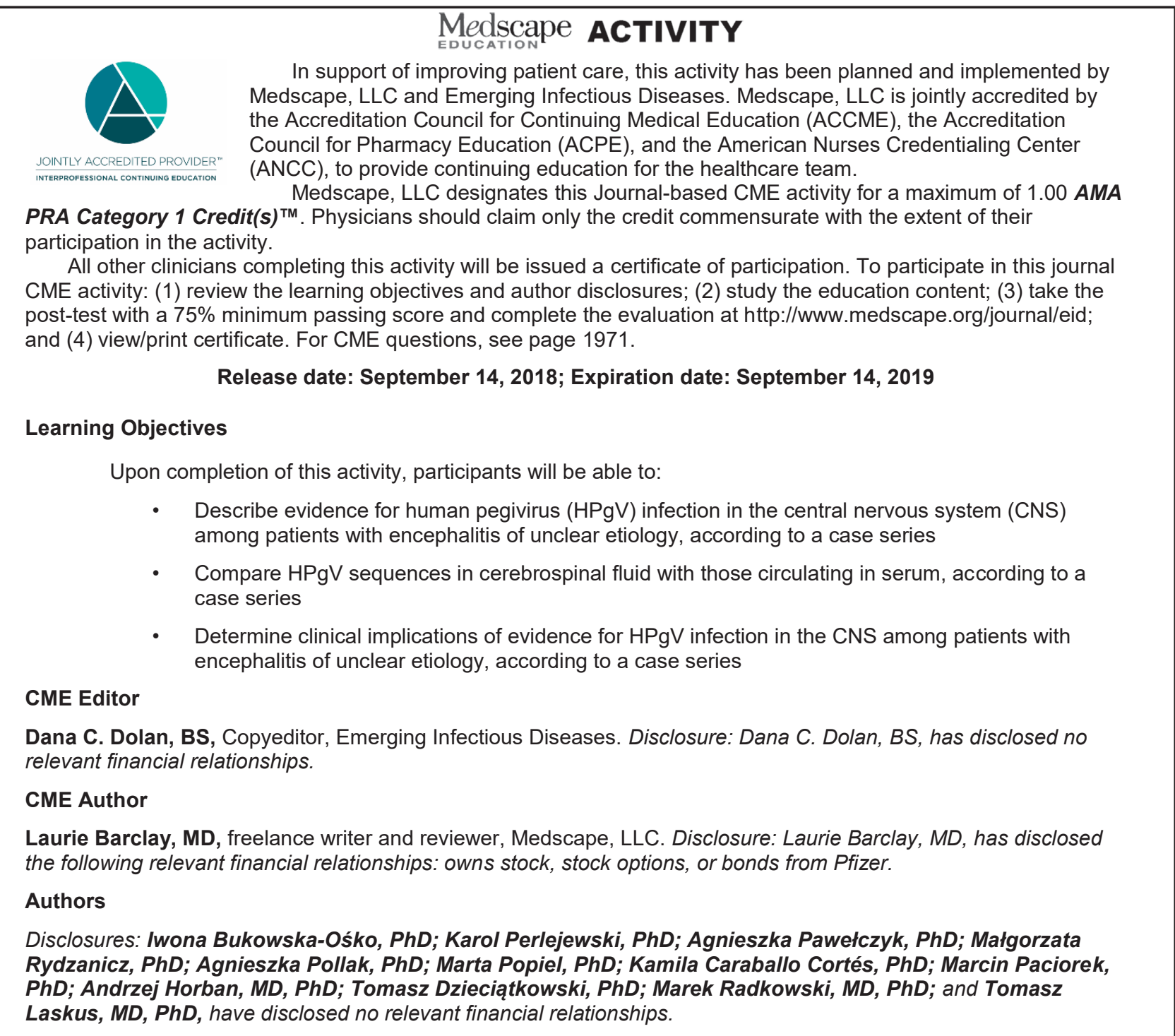

Author affiliations: Medical University of Warsaw, Warsaw, Poland (I. Bukowska-Ośko, K. Perlejewski, A. Pawełczyk, M. Rydzanicz, M. Popiel, K. Caraballo Cortés, M. Paciorek, A. Horban,

T. Dzieciątkowski, M. Radkowski, T. Laskus); Institute of

Physiology and Pathology of Hearing, Kajetany, Poland (A. Pollak)

DOI: https://doi.org/10.3201/eid2410.180161
Human pegivirus (HPgV), previously called hepatitis $\mathrm{G}$ virus or $\mathrm{GB}$ virus $\mathrm{C}$, is a lymphotropic virus with undefined pathology. Because many viruses from the family Flaviviridae, to which HPgV belongs, are neurotropic, we studied whether HPgV could infect the central nervous system. We tested serum and cerebrospinal fluid samples from 96 patients with a diagnosis of encephalitis for a variety of 
pathogens by molecular methods and serology; we also tested for autoantibodies against neuronal antigens. We found HPgV in serum and cerebrospinal fluid from 3 patients who had encephalitis of unclear origin; that is, all the markers that had been tested were negative. Singlestrand confirmation polymorphism and next-generation sequencing analysis revealed differences between the serum and cerebrospinal fluid-derived viral sequences, which is compatible with the presence of a separate HPgV compartment in the central nervous system. It is unclear whether HPgV was directly responsible for encephalitis in these patients.

$\mathrm{H}^{2}$ uman pegivirus $(\mathrm{HPgV})$ was originally described as a hepatitis virus by 2 independent groups of researchers and called $\mathrm{GB}$ virus $\mathrm{C}$ and hepatitis $\mathrm{G}$ virus $(1,2)$. Whereas the infection was found to be common in patients with forms of chronic hepatitis, and particularly prevalent in patients with chronic hepatitis $\mathrm{C}$ infection, it is not associated with liver injury in the absence of concomitant infection with hepatitis $\mathrm{C}$ virus (HCV) or hepatitis B virus (HBV). Furthermore, the liver is not the primary replication site for this virus $(3,4)$. This virus was recently renamed as pegivirus and assigned to a new genus (Pegivirus) within the family Flaviviridae (5).

Infection with $\mathrm{HPgV}$ is common worldwide; $\approx 5 \%$ of healthy blood donors in industrialized countries are viremic, whereas in some developing countries the prevalence of viremia among blood donors is $\approx 20 \%(6)$._There is evidence that $\mathrm{HPgV}$ is transmitted parenterally, sexually, and also vertically from mother to child (7). However, the high proportion of $\mathrm{HPgV}$ infection in apparently healthy blood donors and the general population suggests existence of nonparenteral routes. The reasons for the high prevalence of infection in developing countries are not entirely clear but could be related to overall poor hygienic conditions, as well as to the time of exposure. In sub-Saharan Africa, where $\mathrm{HPgV}$ is particularly common, this virus is transmitted mainly during childhood, which may facilitate the establishment of chronic infection (7). Because no association between $\mathrm{HPgV}$ and disease has been consistently identified, blood donors are not routinely screened for the virus.

Interest in the $\mathrm{HPgV}$ infection was revived when several studies identified its beneficial effect on the survival of HIV-infected persons $(8,9)$; anti-HIV replication effects of $\mathrm{HPgV}$ were confirmed in vitro (8). Several in vivo and in vitro studies suggest that $\mathrm{HPgV}$ may directly interfere with HIV replication and affect host cell factors necessary for the HIV life cycle; specific mechanisms include modulation of cytokine and chemokine release and receptor expressions and lowering of T-cell activation and proliferation (9). However, infection with
$\mathrm{HPgV}$ may not be totally benign; some studies found an association between infection and non-Hodgkin lymphoma $(10,11)$, which could be the result of lowered immune activation.

Many viruses from the family Flaviviridae, most prominently arthropodborne viruses (arboviruses) such as West Nile virus (WNV) and tick-borne encephalitis virus (TBEV), are neurotropic and a prominent cause of encephalitis in Europe and North America (12). These factors raise the question whether $\mathrm{HPgV}$ could be neurotropic and whether it could be an etiologic agent in neuroinfections. Of note, despite substantial progress in diagnostics, the etiology of encephalitis remains unclear in $40 \%-80 \%$ of patients $(13,14)$. A plethora of pathogens may cause encephalitis; many of these pathogens are rare and thus testing is not performed to identify them, and others have not yet been identified.

Three recent case reports described $\mathrm{HPgV}$ RNA in the human central nervous system (CNS), demonstrating that the virus can be present in the brain under certain circumstances (15-17). In the first study, viral sequences were detected postmortem in brain tissue from a patient with multiple sclerosis, not encephalitis (15). In the second study, the presence of $\mathrm{HPgV}$ might have been related to a severely compromised blood-brain barrier; the patient was HIV-positive and had cerebral toxoplasmosis and fungal encephalitis (16). Although the full-length virus was recovered from the patient's brain tissue, it is unclear which cells harbored the virus and it was possible that the actual source was blood. Furthermore, the association of $\mathrm{HPgV}$ with multiple sclerosis could not be established because the study was limited to a single case. In the third study, $\mathrm{HPgV}$ was detected in serum and CSF of a patient with a severe form of encephalitis of unclear origin (17). Of these 3 studies, none included comparison of serum- and CNSderived virus. We conducted a study of 96 consecutive patients with diagnosis of encephalitis (18) in Poland during 2012-2015 to determine whether HPgV could be found in the CNS.

\section{Materials and Methods}

\section{Patients and Routine Diagnostics}

We prospectively enrolled patients with encephalitis at the Warsaw Hospital for Infectious Diseases (Warsaw, Poland) from June 2012 through July 2015. The details of this study were published previously (18). We defined encephalitis as an acute-onset illness with altered mental status, decreased level of consciousness, seizures, or focal neurologic signs, together with $\geq 1$ abnormality of the CSF (leukocyte count $\geq 4$ cells $/ \mathrm{mm}^{2}$ or protein level $\geq 40$ $\mathrm{mg} / \mathrm{dL}$ ). We obtained written informed consent from all patients or from close relatives of patients unable to give 
consent due to their condition. The Internal Review Board of the Medical University of Warsaw approved the study.

We collected CSF and serum samples from patients at admission (5-7 days after symptom onset) and kept them frozen at $-80^{\circ} \mathrm{C}$ until analysis. We tested the samples from all 96 patients for the presence of $5^{\prime}$ untranslated region (UTR) HPgV RNA. We performed real-time quantitative PCR (qPCR) or real-time quantitative reverse transcription PCR (qRT-PCR) to detect human herpesvirus (HHV) 1 and 2, varicella zoster virus (VZV), cytomegalovirus (CMV), HHV-6, enteroviruses (coxsackievirus A9, A16, B2, B3, B4, B5; echovirus 5, 6, 9, 11, 18, 30; and enterovirus 71 ), TBEV, WNV, and human adenovirus (HAdV) in CSF samples. We used commercial serologic tests to test CSF and paired serum samples for HHV-1, HHV-2, VZV, TBEV, and WNV as described (18). We detected autoantibodies against neuronal surface antigens using the Autoimmune Encephalitis Mosaic 6 assay (Euroimmun AG, Luebeck, Germany).

\section{HPgV 5' UTR and E2 Amplification}

We extracted total RNA with TRIzol LS (ThermoFisher Scientific, Waltham, MA, USA) from $400 \mu \mathrm{L}$ of CSF or serum and suspended RNA in $20 \mu \mathrm{L}$ of water, $5 \mu \mathrm{L}$ of which was subsequently used for each amplification reaction. We amplified the HPgV 5' UTR by nested reverse transcription PCR (RT-PCR) as described previously (19), resulting in 421 bp-length product; we amplified the E2 region following the RT-PCR protocol published by Smith et al. (20). The final product was $422 \mathrm{bp}$ in length.

\section{Single-Strand Conformation Polymorphism}

We subjected the amplified PCR products to single-strand conformational polymorphism analysis, as described previously (21). In brief, we purified HPgV 5' UTR and HPgVE2 PCR products by using the Wizard PCR Preps DNA Purification System (Promega, Madison, WI, USA). We then subjected the products to thermal denaturation, ran them on nondenaturing $1 \%$ polyacrylamide gels at $400 \mathrm{~V}$ in $25^{\circ} \mathrm{C}$, fixed them with acetic acid, and stained them with silver stain.

\section{Next-Generation Sequencing}

We reamplified RT-PCR products with primers specifically designed for the Illumina MiSeq platform (Illumina, San Diego, CA, USA). Each primer contained the following: sequences complementary to the adapters on a flow cell; an 8-nt index sequence; sequences corresponding to the Illumina sequencing primers; and sequence-specific nested primers for the 5' UTR and E2 region. Amplification of the $5^{\prime}$ UTR region included initial denaturation at $94^{\circ} \mathrm{C}$ for 5 min, 20 cycles of $94^{\circ} \mathrm{C}$ for $1 \mathrm{~min}, 58^{\circ} \mathrm{C}$ for $1 \mathrm{~min}, 72^{\circ} \mathrm{C}$ for $1 \mathrm{~min}$, and final elongation at $72^{\circ} \mathrm{C}$ for $10 \mathrm{~min}$. $\mathrm{HPgV}$ E2 amplification included denaturation at $94^{\circ} \mathrm{C}$ for $5 \mathrm{~min}$ followed by 20 cycles of $94^{\circ} \mathrm{C}$ for $18 \mathrm{~s}, 55^{\circ} \mathrm{C}$ for $20 \mathrm{~s}, 72^{\circ} \mathrm{C}$ for $90 \mathrm{~s}$, and 1 cycle at $72^{\circ} \mathrm{C}$ for $10 \mathrm{~min}$. We trimmed the libraries by using the LabChip XT apparatus (PerkinElmer, Waltham, Massachusetts, USA) with the DNA 300 Assay Kit (PerkinElmer); the range of fraction collection was $370-430 \mathrm{bp}$ for $5^{\prime}$ UTR and 460-530 bp for E2.

We assessed the quality and average length of nextgeneration sequencing libraries by using Bioanalyzer (Agilent Technologies, Santa Clara, CA, USA). We equimolarily pooled the indexed samples and sequenced them on Illumina MiSeq with $301 \mathrm{bp}$-end reads according to the manufacturer's protocol.

\section{Data Analysis}

We trimmed raw reads using cutadapt version 1.2.1 (https://github.com/marcelm/cutadapt/); (22), then used FASTX-Toolkit (http://hannonlab.cshl.edu/fastx_toolkit/ index.html) for additional processing. We removed all Phred quality score reads $<20$ using FASTQ/A Artifacts Filter and preprocessed the remaining reads (grouping, counting, and frequency arrangement) using $\mathrm{R}$ scripts (23). To diminish the contribution of false positive variants to genetic diversity, we applied the experimentally established sequencing error cutoff of $1.22 \%$. Finally, we aligned remaining sequences and generated phylogenic trees with ClustalX version 2.0 (http://www.clustal.org/ clustal2/) (24). We assessed nucleotide diversity per site and the number of substitutions with respect to the dominant serum sequence in each patient using DnaSP version 6.11.06 (25). We predicted the RNA secondary structures of the 5' UTR using Mfold version 3.2 (http://unafold. rna.albany.edu/?q=mfold) (26), and searched for putative B cell epitopes within the E2 region using BepiPred-2.0 (http://www.cbs.dtu.dk/services/BepiPred/) (27).

\section{Results}

Four patients were positive for 5' UTR HPgV RNA in serum, and 3 of these patients were also positive in CSF. We analyzed the samples from those 3 patients; their samples were collected at admission, which was 5-7 days after symptom onset. We diagnosed encephalitis of unclear origin for all 3 patients because they were negative for all the pathogens tested (Table 1). The small number of HP$\mathrm{gV}$-infected patients did not allow for statistical analysis, but these patients were not strikingly different from other encephalitis patients. We initially suspected 1 patient, who had a severe illness with prolonged hospitalization, of having HHV infection, but tests did not confirm HHV. All 3 patients recovered without any neurologic sequelae.

We compared serum- and CSF-derived 5' UTR and E2 amplicons from the 3 patients by single-strand conformational polymorphism analysis (Figure 1). Because this 
Table 1. Comparison of clinical characteristics of 3 encephalitis patients infected with human pegivirus compared with patients with other forms of encephalitis, Poland, 2012-2015*

\begin{tabular}{|c|c|c|c|c|c|}
\hline \multirow[b]{3}{*}{ Characteristic } & \multirow{2}{*}{\multicolumn{3}{|c|}{$\begin{array}{l}\text { Encephalitis patients infected } \\
\text { with pegivirus }\end{array}$}} & \multicolumn{2}{|c|}{ Other encephalitis patients } \\
\hline & & & & \multirow{2}{*}{$\begin{array}{l}\text { Infectious cause } \\
\text { identified, } \mathrm{n}=41 \dagger\end{array}$} & \multirow{2}{*}{$\begin{array}{c}\text { Unknown cause or } \\
\text { autoimmune illness, } \mathrm{n}=52 \ddagger\end{array}$} \\
\hline & Patient 1 & Patient 2 & Patient 3 & & \\
\hline Male sex & No & No & Yes & $30(73)$ & $23(44)$ \\
\hline Median age, y (range) & 55 & 28 & 20 & $38(19-85)$ & $38(20-82)$ \\
\hline $\begin{array}{l}\text { Pharmacological immunosuppression } \\
\text { present }\end{array}$ & 0 & 0 & 0 & $2(5)$ & $3(6)$ \\
\hline HIV positive & 0 & 0 & 0 & 0 & $2(4)$ \\
\hline Cancer & 0 & 0 & 0 & $6(15)$ & $1(2)$ \\
\hline Median length of hospital stay, d (range) & 41 & 30 & 8 & $12(5-97)$ & $11.5(6-79)$ \\
\hline Fever $\geq 38^{\circ} \mathrm{C}$ & Yes & Yes & No & $26(63)$ & $18(35)$ \\
\hline Headache & Yes & Yes & No & $22(54)$ & $25(48)$ \\
\hline Altered mental status & Yes & Yes & No & $36(88)$ & $47(85)$ \\
\hline Focal neurologic signs & No & No & Yes & $9(22)$ & $10(20)$ \\
\hline Seizures & No & No & Yes & $12(29)$ & $16(31)$ \\
\hline Stiff neck & No & No & No & $7(17)$ & $12(23)$ \\
\hline \multicolumn{6}{|l|}{ CSF analysis } \\
\hline Median leukocyte count, cells $/ \mathrm{mm}^{2}$ (range) & 3 & 4 & 3 & $41(1-1225)$ & $18(1-362)$ \\
\hline Median protein level, g/L (range) & 0.68 & 0.26 & 1.63 & $0.57(0.16-3.21)$ & $0.56(0.11-3.33)$ \\
\hline Death & 0 & 0 & 0 & $1(2.4)$ & 0 \\
\hline \multicolumn{6}{|c|}{$\begin{array}{l}\text { *Values are no. }(\%) \text { unless otherwise indicated. CSF, cerebrospinal fluid } \\
\text { †ldentified infections were human herpesvirus } 1(n=22) \text {, enterovirus }(n=6) \text {, varicella zoster virus }(n=5) \text {, tick-borne encephalitis virus }(n=6) \text {, and } \\
\text { cytomegalovirus }(n=2) \text {. } \\
\text { †All markers of viral infection were negative, but } 5 \text { patients had antibodies against N-methyl-D-aspartate receptor and a diagnosis of autoimmune } \\
\text { encephalitis. }\end{array}$} \\
\hline
\end{tabular}

analysis suggested the presence of differences between the serum- and CSF-derived viral sequences in individual patients, we subjected all amplicons to next-generation sequencing. After filtering, the mean number of reads per sample was 70,759 (range 2,706-183,046) (Table 2).

When we compared 5' UTR and E2 sequences phylogenetically, we found that serum- and CSF-derived sequences clustered together in individual patients; no sequence was found in multiple patients (Figure 2). Of note, we found several variants to be unique in the CSF compartment. These sequences comprised $2.28 \%$ $29.32 \%$ of all variants for $5^{\prime}$ UTR and $0 \%-41.78 \%$ of all variants for E2 (Table 2; Figure 3). Unique CSF-derived sequences were also present when we analyzed the E2 region on the amino acid level (Figure 4). The changes were serine to phenylalanine at aa position 508 in patient 2 and proline to leucine at position 572 in patient 3 . Both changes were within the predicted $\mathrm{B}$ cell epitopes (aa 506-522 and 559-572).

We analyzed all 5' UTR sequence variants to determine the predicted stability of their secondary RNA structure. We deemed the effect of variations minor because most were localized in the nonbasepaired parts (data not shown), and free energies of the hypothetical secondary structures were only occasionally and mildly affected (online Technical Appendix Figure, https://wwwnc.cdc.gov/ EID/article/24/10/18-0161-Techapp1.pdf) (28).

\section{Discussion}

We detected $\mathrm{HPgV}$ sequences in CSF from 3/96 patients with encephalitis. We classified all 3 cases as encephalitis

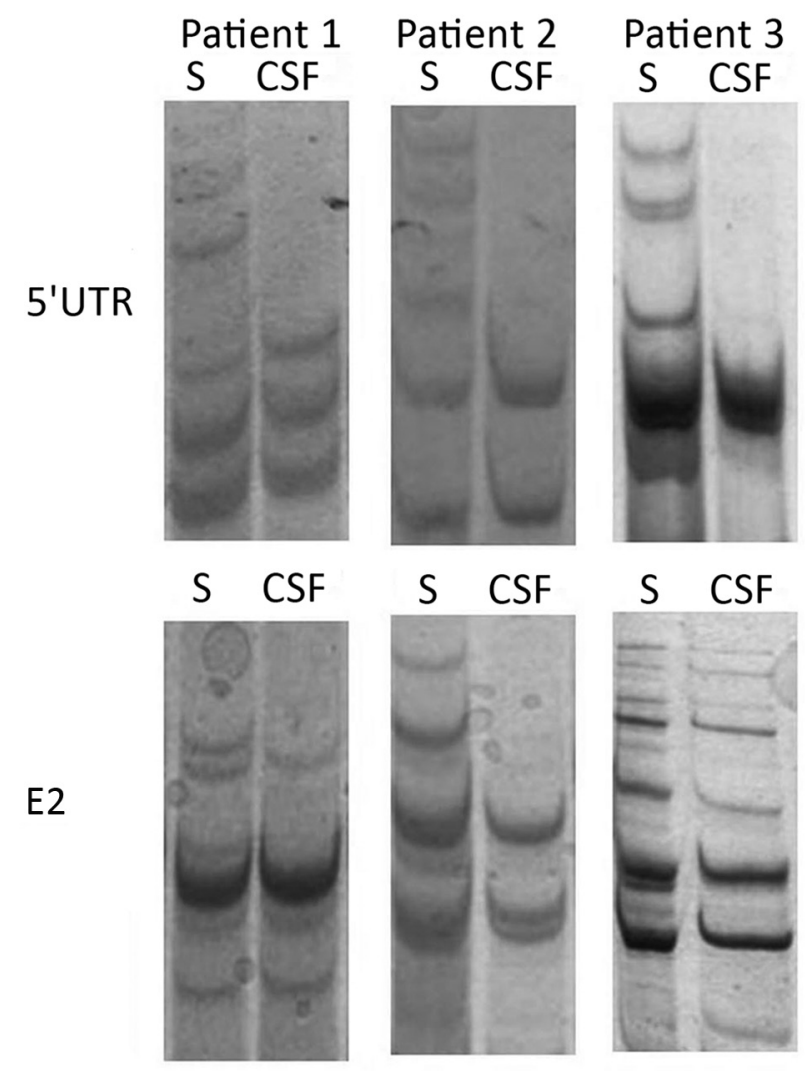

Figure 1. Single-strand conformation polymorphism analysis of 5' UTR and E2 region human pegivirus amplicons from 3 patients with encephalitis of unclear origin, Poland, 2012-2015. CSF, cerebrospinal fluid; S, serum; UTR, untranslated region. 
Table 2. 5 Human pegivirus variants in serum and cerebrospinal fluid in 3 patients with encephalitis of unknown origin, Poland, 2012-2015*

\begin{tabular}{|c|c|c|c|c|c|c|}
\hline \multirow[b]{2}{*}{ RNA region } & \multicolumn{2}{|c|}{ Patient 1} & \multicolumn{2}{|c|}{ Patient 2} & \multicolumn{2}{|c|}{ Patient 3} \\
\hline & Serum & CSF & Serum & CSF & Serum & CSF \\
\hline \multicolumn{7}{|l|}{$5^{\prime}$ untranslated region } \\
\hline No. reads before error cutoff & 124,987 & 110,331 & 108,002 & 183,046 & 101,240 & 145,411 \\
\hline No. reads after error cutoff & 61,783 & 57,668 & 49,075 & 109,061 & 55,328 & 75,998 \\
\hline No. nucleotide variants $\dagger$ & 3 & 7 & 3 & 3 & 2 & 3 \\
\hline No. unique nucleotide variants in CSF† & - & $5(29.32)$ & - & $1(2.28)$ & - & $1(2.49)$ \\
\hline No. nucleotide substitutions & 2 & 7 & 2 & 2 & 1 & 2 \\
\hline Nucleotide diversity per site & 0.004 & 0.007 & 0.004 & 0.004 & 0.003 & 0.004 \\
\hline \multicolumn{7}{|l|}{ E2 region } \\
\hline No. reads before error cutoff & 70,460 & 38,025 & 77,656 & 76,918 & 2,706 & 82,738 \\
\hline No. reads after error cutoff & 26,720 & 20,619 & 26,558 & 42,609 & 453 & 34,887 \\
\hline No. nucleotide variants $†$ & 8 & 4 & 8 & 9 & 4 & 7 \\
\hline No. unique nucleotide variants in CSF† & - & 0 & - & $5(41.78)$ & - & $3(27.28)$ \\
\hline No. nucleotide substitutions & 4 & 2 & 5 & 5 & 2 & 3 \\
\hline Nucleotide diversity per site & 0.007 & 0.004 & 0.006 & 0.007 & 0.004 & 0.005 \\
\hline No. amino acid variants $\dagger$ & 2 & 2 & 2 & 5 & 2 & 4 \\
\hline No. unique amino acid variants in CSF† & - & 0 & - & $3(27.28)$ & - & $2(27.28)$ \\
\hline
\end{tabular}

†After applying the $1.22 \%$ sequencing error cutoff.

of unknown origin because they were negative for serologic and molecular markers of common CNS pathogens. Furthermore, we demonstrated that these viral sequences differed from those circulating in serum. The presence of viral RNA in CSF could be due to a compromised blood-brain barrier, which was possible in these patients with encephalitis. However, the presence of differences in circulating and CSF-derived sequences is more compatible with the existence of separate viral compartments and thus independent replication. Similar compartmentalization in which distinct blood and CNS viral populations indicate separately evolving populations has been described for other viruses, most prominently for HIV (29) but also for $\mathrm{HCV}$ $(30,31)$ and human BK polyomavirus (32).

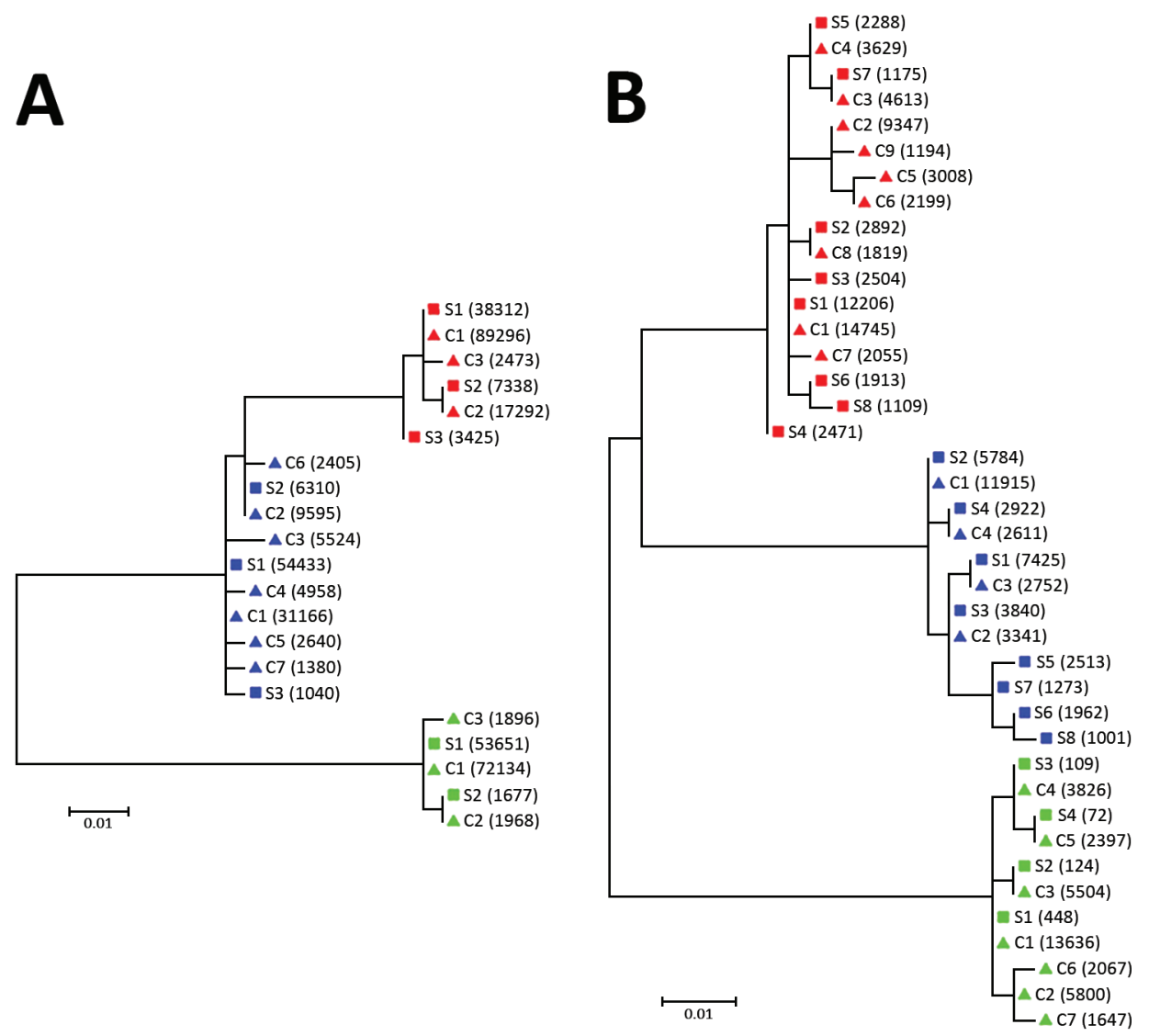

Figure 2. Phylogenetic analysis of A) $5^{\prime}$ UTR and B) E2 region sequences of human pegivirus from 3 patients with encephalitis of unclear origin, Poland, 2012-2015. Phylogenic trees were generated using ClustalX version 2.0 (http://www.clustal. org/clustal2/). Viral variant frequencies follow haplotype number. Red indicates patient 1; blue, patient 2; green, patient 3. Scale bars indicate number of nucleotide substitutions per site. C, cerebrospinal fluid; S, serum; UTR, untranslated region. 


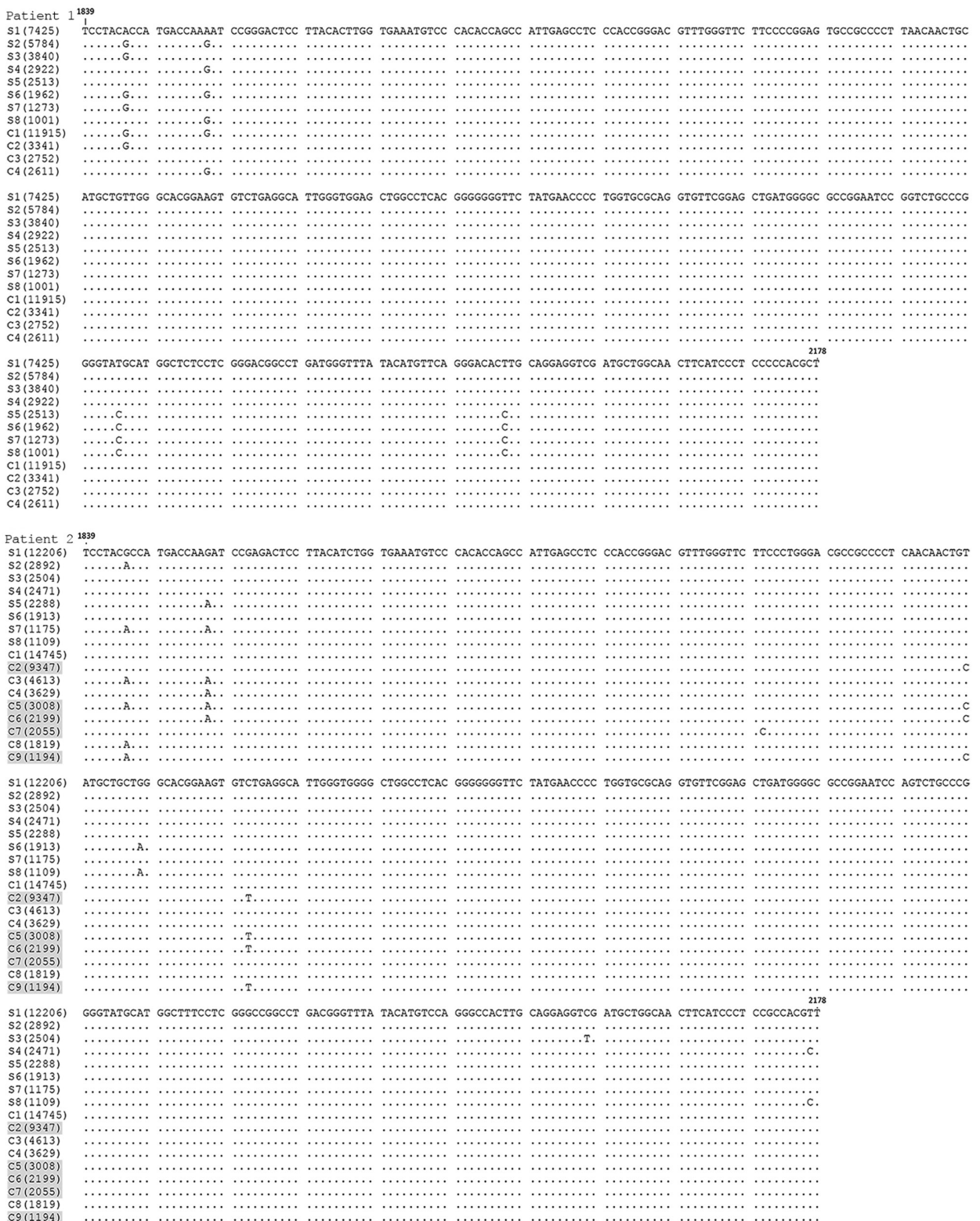

Figure 3. Comparison of E2 region human pegivirus sequences amplified from serum and cerebrospinal fluid from 3 patients with encephalitis of unclear origin, Poland, 20122015. Numbers in parentheses represent the number of reads representing a given sequence. Shading indicates sequences unique to cerebrospinal fluid. Nucleotide numbering follows the reference strain published by Linnen et al (2) (GenBank accession no. NC_001710.1). C, cerebrospinal fluid; S, serum.

Patient 31839

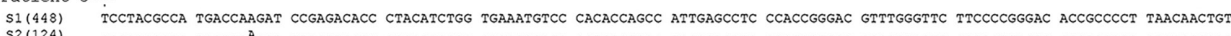
S2(124)

S3 $(109)$
S4 (72)

C2 $(13636)$

$\frac{\mathrm{C} 2(5800)}{\mathrm{C} 3(5504)}$ $\mathrm{C} 4(3826)$
$\mathrm{C} 5(2397)$

C6 (2067)

S1 (448)

S3(109)

S3(109)
S4 (72)

C1(13636)

$\mathrm{C} 2(5800)$

C4 $4(3826)$

C5 (2397)
C6 (2067)

C7 (1647)

S1 (448)
S2 (124)

S2 (124)
S3 (109)

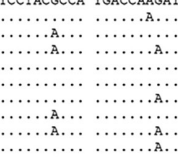

ATGCTCTTGG GCACGGAAGT GTCCGAAGCA CTTGGCGGGG CTGGTCTCAC GGGGGGGTTC TATGAACCCC TGGTGCGCAG GTGTTCGGAG CTGATGGGAC GCCGCAATCC AGTCTGTCCG .............................

…...........

GGGTTTGCAT GGCTCTCCTC GGGCAGACCT GACGGGTTPA TACATGTTCA GGGCCACTTG CAGGAGGTAG ATGCTGGCAA CTTCATCCCT CCTCCACGCT 
461

SYTMTKIRDSLHLVKCPTPAIEPPTGTFGFFPGVPPLNNCMLLGTEVSEALGGAGLTGGFYEPLVRRCSELMGRRNPVCPGYAWLSSGRPDGFIHVQGHLQEVDAGNFIPPPR

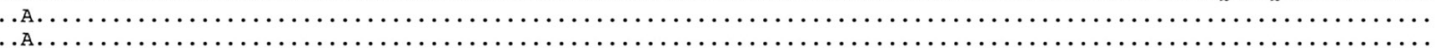

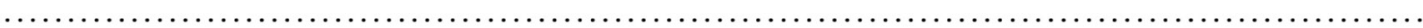
A

А

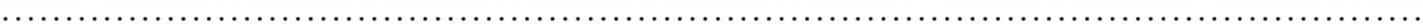
A.

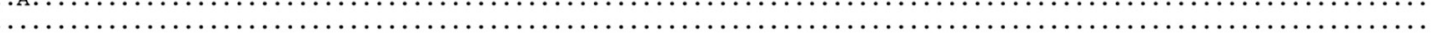
461

'SYAMTKIRDSLHLVKCPTPAIEPPTGTFGFFPGTPPLNNCMLLGTEVSEALGGAGLTGGFYEPLVRRCSELMGRRNPVCPGYAWLSSGRPDGFIHVQGHLQEVDAGNFIPPPR'

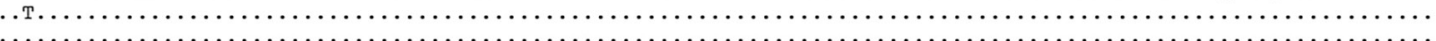


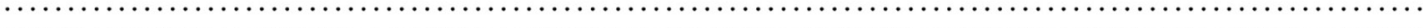
, т.

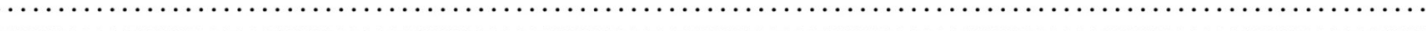

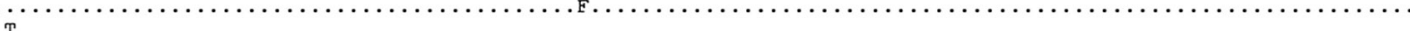

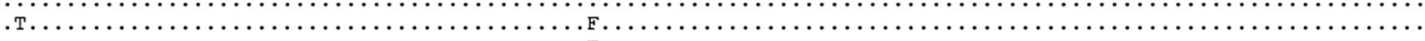

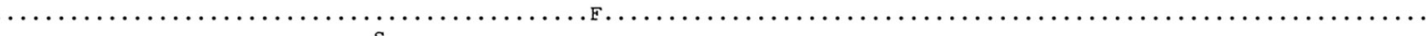

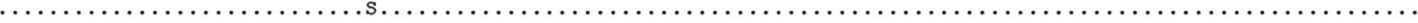
(1.

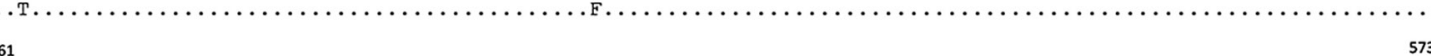
S'YAMTKIRDTLHLVKCPTPAIEPPTGTFGFFPGTPPLNNCMLLGTEVSEALGGAGLTGGFYEPLVRRCSELMGRRNPVCPGFAWLSSGRPDGFIHVQGHLQEVDAGNFIPPPR

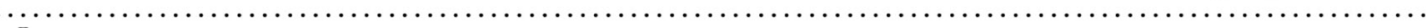
т т. т. 

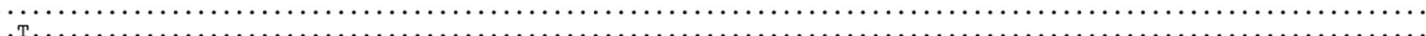
т. т.

Figure 4. Comparison of amino acid composition of E2 region human pegivirus sequence variants amplified from serum and cerebrospinal fluid from 3 patients with encephalitis of unclear origin, Poland, 2012-2015. Numbers in parentheses represent the number of reads representing a given sequence. Shading indicates sequences unique to cerebrospinal fluid. C, cerebrospinal fluid; $\mathrm{S}$, serum.

It is unclear how $\mathrm{HPgV}$ could access the CNS. Although initially $\mathrm{HPgV}$ was thought to be a hepatotropic virus, the viral negative strand, which is the putative replicative intermediate of the virus, was not detected in liver tissue (3); however, it was found in bone marrow and spleen $(33,34)$. The virus is now considered lymphotropic because it can be detected at a low level in multiple lineages of peripheral leukocytes $(35,36)$, and it has been speculated that the primary target could be a progenitor hematopoietic stem cell. The route for CNS access could be through infected leukocytes; all basic groups ( $\mathrm{T}$ cells, B cells, macrophage/monocytes, and NK cells) have the ability to enter the brain under certain conditions (37). Certain monocyte family members are constantly replaced as part of normal physiology $(38,39)$, while the entry of $\mathrm{T}$ cells and B cells depends largely on their activation state $(40,41)$. Such a phenomenon related to trafficking of infected leukocytes through the blood-brain barrier has been long postulated for HIV-1 neuroinfection (42).

Whether HPgV was the causative factor of encephalitis in the patients we describe is not clear. Viral pathogens are typically present only transiently in CSF and this window could be easily missed, particularly when the spinal tap is done too late in the course of illness (43). If $\mathrm{HPgV}$ encephalitis exists, it could be a rare phenomenon. In a previous study of 17 encephalitis and aseptic meningitis cases of unknown cause, no CSF sample was positive (44). However, even infections with well-known neurotropic agents from the Flaviviridae family, such as WNV or TBEV, are usually subclinical or asymptomatic; clinical signs and symptoms develop only in 5\%-30\% of cases $(45,46)$. Of note, in 2 of the cases we describe, the encephalitis was mild, and all 3 patients recovered without any neurologic sequelae. Obviously, the mere presence of a pathogen in the CNS in patients with encephalitis does not prove causality; for example, $\mathrm{HCV}$ sequences are commonly detected in brain and CSF of infected patients without any accompanying evidence of encephalitis (29). In our study, we detected $\mathrm{HPgV}$ sequences in CSF only in patients without an obvious cause of encephalitis and in none of the patients in whom a known pathogen was identified. 
The identified 5' UTR and E2 region sequence differences between CSF and serum compartments could have biological meaning. The $5^{\prime}$ UTR contains an internal ribosomal entry site that allows cap-independent viral translation (28). Such structures were identified within the 5 ' UTR of the picornaviruses and were shown to interact with cellular proteins, thus affecting the host range of individual viruses (47). Research has also shown that, for $\mathrm{HCV}$, translation efficiencies of brain-derived internal ribosomal entry site variants are generally lower than those found in serum, which could be a viral strategy favoring latency in the CNS (31). Taking this into consideration, we speculated that at least some of the $5^{\prime}$ UTR changes in the patients we report represent tissue-specific adjustment. Viral adaptive changes could be relatively small and yet make a huge difference; for example, it has been demonstrated for lymphocytic choriomeningitis virus in mice that variants differing by a single amino acid substitution are competitively selected either by the liver and spleen or by neurons (48).

On the amino acid level, we saw 2 unique E2 region changes in CSF variants compared with serum: in patient 2 , serine was changed to phenylalanine at aa position 508, and in patient 3, proline was changed to leucine at position 572. Both were within regions predicted to contain B-cell epitopes, thus suggesting that they were the effect of immune pressure. Furthermore, the change in patient 3 was located in the region of E2 that was experimentally shown to contain a strong antigenic site and likely to be involved in cell binding or fusion (49).

RNA viruses in particular are characterized by a high degree of genetic heterogeneity; probably because the lack of proofreading $3^{\prime} 5^{\prime}$ exonuclease activity in viral RNA polymerases causes low fidelity. As a result, viruses circulate in the infected host as a population of closely related but nonidentical genomes, referred to as quasispecies (50). It is unclear whether the observed high HPgV variability developed in the patients we describe de novo after infection or if most or all variants were transmitted from the infecting host; both mechanisms could occur together. However, because viral transmission is typically accompanied by narrowing of the quasispecies spectrum (known as the bottleneck phenomenon), some extent of postinfection evolution is highly likely.

In summary, we detected $\mathrm{HPgV}$ sequences in the CSF of 3 patients with encephalitis of unclear origin, and these sequences from CSF differed from those circulating in serum. These findings are compatible with the presence of a separate viral compartment in the CNS. Determining if the pegivirus was responsible for encephalitis or if it was present along with another cause of encephalitis will require further research, including histopathological analysis.
This work was supported by Polish National Science Center (grants 2017/25/B/NZ6/01463 and DEC-2013/11/N/NZ6/00961), the Foundation for Polish Science (grant POMOST/2013-7/2), and Infectious Diseases Hospital Foundation.

\section{About the Author}

Dr. Bukowska-Ośko is a scientist in the Department of Immunopathology of Infectious and Parasitic Diseases at Medical University of Warsaw, Poland. Her primary research interests include molecular pathogenesis of hepatitis $\mathrm{C}$, application of metagenomics in diagnostics of infectious diseases and brain infections.

\section{References}

1. Simons JN, Leary TP, Dawson GJ, Pilot-Matias TJ, Muerhoff AS, Schlauder GG, et al. Isolation of novel virus-like sequences associated with human hepatitis. Nat Med. 1995;1:564-9. http://dx.doi.org/10.1038/nm0695-564

2. Linnen J, Wages J Jr, Zhang-Keck ZY, Fry KE, Krawczynski KZ, Alter $\mathrm{H}$, et al. Molecular cloning and disease association of hepatitis $\mathrm{G}$ virus: a transfusion-transmissible agent. Science. 1996;271:505-8. http://dx.doi.org/10.1126/science.271.5248.505

3. Laskus T, Radkowski M, Wang LF, Vargas H, Rakela J. Lack of evidence for hepatitis $\mathrm{G}$ virus replication in the livers of patients coinfected with hepatitis C and G viruses. J Virol. 1997; 71:7804-6.

4. Pessoa MG, Terrault NA, Detmer J, Kolberg J, Collins M, Hassoba HM, et al. Quantitation of hepatitis $\mathrm{G}$ and $\mathrm{C}$ viruses in the liver: evidence that hepatitis $\mathrm{G}$ virus is not hepatotropic. Hepatology. 1998;27:877-80. https://dx.doi.org/10.1002/hep.510270335

5. Adams MJ, King AM, Carstens EB. Ratification vote on taxonomic proposals to the International Committee on Taxonomy of Viruses (2013). Arch Virol. 2013;158:2023-30. http://dx.doi.org/10.1007/ s00705-013-1688-5

6. Mohr EL, Stapleton JT. GB virus type C interactions with HIV: the role of envelope glycoproteins. J Viral Hepat. 2009;16:757-68. http://dx.doi.org/10.1111/j.1365-2893.2009.01194.x

7. Mphahlele MJ, Lau GK, Carman WF. HGV: the identification, biology and prevalence of an orphan virus. Liver. 1998;18:143-55. http://dx.doi.org/10.1111/j.1600-0676.1998.tb00142.x

8. Xiang J, Wünschmann S, Diekema DJ, Klinzman D, Patrick KD, George SL, et al. Effect of coinfection with GB virus C on survival among patients with HIV infection. N Engl J Med. 2001;345: 707-14. http://dx.doi.org/10.1056/NEJMoa003364

9. Bhattarai N, Stapleton JT. GB virus C: the good boy virus? Trends Microbiol. 2012;20:124-30. http://dx.doi.org/10.1016/ j.tim.2012.01.004

10. Nakamura S, Takagi T, Matsuda T. Hepatitis G virus RNA in patients with B-cell non-Hodgkin's lymphoma. Br J Haematol. 1997;98:1051-2.

11. Krajden M, Yu A, Braybrook H, Lai AS, Mak A, Chow R, et al. GBV-C/hepatitis G virus infection and non-Hodgkin lymphoma: a case control study. Int J Cancer. 2010;126:2885-92.

12. Leyssen P, De Clercq E, Neyts J. Perspectives for the treatment of infections with Flaviviridae. Clin Microbiol Rev. 2000;13:67-82. http://dx.doi.org/10.1128/CMR.13.1.67-82.2000

13. Granerod J, Crowcroft NS. The epidemiology of acute encephalitis. Neuropsychol Rehabil. 2007;17:406-28. http://dx.doi.org/10.1080/ 09602010600989620

14. Granerod J, Tam CC, Crowcroft NS, Davies NW, Borchert M, Thomas SL. Challenge of the unknown. A systematic review of acute encephalitis in non-outbreak situations. Neurology. 2010; 75:924-32. http://dx.doi.org/10.1212/WNL.0b013e3181f11d65 
15. Kriesel JD, Hobbs MR, Jones BB, Milash B, Nagra RM, Fischer KF. Deep sequencing for the detection of virus-like sequences in the brains of patients with multiple sclerosis: detection of GBV-C in human brain. PLoS One. 2012;7:e31886. http://dx.doi.org/10.1371/journal.pone.0031886

16. Liu Z, Zhang Y, Wei F, Xu M, Mou D, Zhang T, et al. Detection of $\mathrm{GB}$ virus $\mathrm{C}$ genomic sequence in the cerebrospinal fluid of a HIV-infected patient in China: a case report and literature review. Epidemiol Infect. 2016;144:106-12. http://dx.doi.org/10.1017/ S0950268815001326

17. Fridholm H, Østergaard Sørensen L, Rosenstierne MW, Nielsen H, Sellebjerg F, Bengård Andersen Å, et al. Human pegivirus detected in a patient with severe encephalitis using a metagenomic pan-virus array. J Clin Virol. 2016;77:5-8. http://dx.doi.org/10.1016/ j.jcv.2016.01.013

18. Popiel M, Perlejewski K, Bednarska A, Dzieciątkowski T, Paciorek M, Lipowski D, et al. Viral etiologies in adult patients with encephalitis in Poland: a prospective single center study. PLoS One. 2017;12:e0178481. http://dx.doi.org/10.1371/journal.pone.0178481

19. Laskus T, Radkowski M, Wang LF, Vargas H, Rakela J. Detection of hepatitis $\mathrm{G}$ virus replication sites by using highly strand-specific Tth-based reverse transcriptase PCR. J Virol. 1998;72:3072-5.

20. Smith DB, Basaras M, Frost S, Haydon D, Cuceanu N, Prescott L, et al. Phylogenetic analysis of GBV-C/hepatitis G virus. J Gen Virol. 2000;81:769-80. http://dx.doi.org/10.1099/ 0022-1317-81-3-769

21. Laskus T, Wilkinson J, Gallegos-Orozco JF, Radkowski M, Adair DM, Nowicki M, et al. Analysis of hepatitis C virus quasispecies transmission and evolution in patients infected through blood transfusion. Gastroenterology. 2004;127:764-76. http://dx.doi.org/10.1053/j.gastro.2004.06.005

22. Martin M. Cutadapt removes adapter sequences from highthroughput sequencing reads. EMBnet. 2011;17:10-2 2011. https://dx.doi.org/10.14806/ej.17.1.200

23. Hannon Laboratory. FastX Toolkit. 2015 [cited 2018 Jul 30]. http://hannonlab.cshl.edu/fastx_toolkit/index.html

24. Larkin MA, Blackshields G, Brown NP, Chenna R, McGettigan PA, McWilliam H, et al. Clustal W and Clustal X version 2.0. Bioinformatics. 2007;23:2947-8. http://dx.doi.org/10.1093/ bioinformatics/btm 404

25. Rozas J, Ferrer-Mata A, Sánchez-DelBarrio JC, Guirao-Rico S, Librado P, Ramos-Onsins SE, et al. DnaSP 6: DNA sequence polymorphism analysis of large data sets. Mol Biol Evol. 2017;34:3299-302. http://dx.doi.org/10.1093/molbev/msx248

26. Zuker M. Mfold web server for nucleic acid folding and hybridization prediction. Nucleic Acids Res. 2003;31:3406-15. http://dx.doi.org/10.1093/nar/gkg595

27. Jespersen MC, Peters B, Nielsen M, Marcatili P. BepiPred-2.0: improving sequence-based B-cell epitope prediction using conformational epitopes. Nucleic Acids Res. 2017;45(W1):W24-9. http://dx.doi.org/10.1093/nar/gkx346

28. Simons JN, Desai SM, Schultz DE, Lemon SM, Mushahwar IK. Translation initiation in GB viruses A and C: evidence for internal ribosome entry and implications for genome organization. J Virol. 1996;70:6126-35.

29. Bednar MM, Sturdevant CB, Tompkins LA, Arrildt KT, Dukhovlinova E, Kincer LP, et al. Compartmentalization, viral evolution, and viral latency of HIV in the CNS. Curr HIV/AIDS Rep. 2015;12:262-71. http://dx.doi.org/10.1007/s11904-015-0265-9

30. Radkowski M, Wilkinson J, Nowicki M, Adair D, Vargas H, Ingui $\mathrm{C}$, et al. Search for hepatitis $\mathrm{C}$ virus negative-strand RNA sequences and analysis of viral sequences in the central nervous system: evidence of replication. J Virol. 2002;76:600-8. http://dx.doi.org/10.1128/JVI.76.2.600-608.2002

31. Forton DM, Karayiannis P, Mahmud N, Taylor-Robinson SD, Thomas HC. Identification of unique hepatitis $\mathrm{C}$ virus quasispecies in the central nervous system and comparative analysis of internal translational efficiency of brain, liver, and serum variants. J Virol. 2004;78:5170-83. http://dx.doi.org/10.1128/ JVI.78.10.5170-5183.2004

32. Jørgensen GE, Hammarin AL, Bratt G, Grandien M, Flaegstad T, Johnsen JI. Identification of a unique BK virus variant in the CNS of a patient with AIDS. J Med Virol. 2003;70:14-9. http://dx.doi.org/10.1002/jmv.10370

33. Radkowski M, Kubicka J, Kisiel E, Cianciara J, Nowicki M, Rakela J, et al. Detection of active hepatitis $\mathrm{C}$ virus and hepatitis $\mathrm{G}$ virus/GB virus $\mathrm{C}$ replication in bone marrow in human subjects. Blood. 2000;95:3986-9.

34. Tucker TJ, Smuts HE, Eedes C, Knobel GD, Eickhaus P, Robson SC, et al. Evidence that the GBV-C/hepatitis G virus is primarily a lymphotropic virus. J Med Virol. 2000;61:52-8. http://dx.doi.org/10.1002/(SICI)1096-9071(200005)61:1<52:: AID-JMV8>3.0.CO;2-L

35. Chivero ET, Bhattarai N, Rydze RT, Winters MA, Holodniy M, Stapleton JT. Human pegivirus RNA is found in multiple blood mononuclear cells in vivo and serum-derived viral RNA-containing particles are infectious in vitro. J Gen Virol. 2014;95:1307-19. http://dx.doi.org/10.1099/vir.0.063016-0

36. Chivero ET, Stapleton JT. Tropism of human pegivirus (formerly known as GB virus $\mathrm{C} /$ hepatitis $\mathrm{G}$ virus) and host immunomodulation: insights into a highly successful viral infection. J Gen Virol. 2015;96:1521-32. http://dx.doi.org/10.1099/ vir.0.000086

37. Hickey WF. Leukocyte traffic in the central nervous system: the participants and their roles. Semin Immunol. 1999;11:125-37. http://dx.doi.org/10.1006/smim.1999.0168

38. Hickey WF, Vass K, Lassmann H. Bone marrow-derived elements in the central nervous system: an immunohistochemical and ultrastructural survey of rat chimeras. J Neuropathol Exp Neurol. 1992;51:246-56. http://dx.doi.org/10.1097/ 00005072-199205000-00002

39. Unger ER, Sung JH, Manivel JC, Chenggis ML, Blazar BR, Krivit W. Male donor-derived cells in the brains of female sex-mismatched bone marrow transplant recipients: a Y-chromosome specific in situ hybridization study. J Neuropathol Exp Neurol. 1993;52:460-70. http://dx.doi.org/10.1097/ 00005072-199309000-00004

40. Hickey WF, Hsu BL, Kimura H. T-lymphocyte entry into the central nervous system. J Neurosci Res. 1991;28:254-60. http://dx.doi.org/10.1002/jnr.490280213

41. Knopf PM, Harling-Berg CJ, Cserr HF, Basu D, Sirulnick EJ, Nolan SC, et al. Antigen-dependent intrathecal antibody synthesis in the normal rat brain: tissue entry and local retention of antigen-specific B cells. J Immunol. 1998; 161:692-701.

42. Zheng J, Gendelman HE. The HIV-1 associated dementia complex: a metabolic encephalopathy fueled by viral replication in mononuclear phagocytes. Curr Opin Neurol. 1997;10:319-26. http://dx.doi.org/10.1097/00019052-199708000-00007

43. Davies NW, Brown LJ, Gonde J, Irish D, Robinson RO, Swan AV, et al. Factors influencing PCR detection of viruses in cerebrospinal fluid of patients with suspected CNS infections. J Neurol Neurosurg Psychiatry. 2005;76:82-7. http://dx.doi.org/ 10.1136/jnnp.2004.045336

44. Radkowski M, Przyjalkowski W, Lipowski D, Wang LF, Laskus T. Lack of GB virus $\mathrm{C}$ /hepatitis $\mathrm{G}$ virus sequences in cerebrospinal fluid in patients with central nervous system infections. Scand J Infect Dis. 1998;30:539. http://dx.doi.org/ $10.1080 / 00365549850161647$

45. Kaiser R. Tick-borne encephalitis: clinical findings and prognosis in adults. Wien Med Wochenschr. 2012;162:239-43. http://dx.doi.org/10.1007/s10354-012-0105-0 
46. Růžek D, Dobler G, Donoso Mantke O. Tick-borne encephalitis: pathogenesis and clinical implications. Travel Med Infect Dis. 2010;8:223-32. http://dx.doi.org/10.1016/j.tmaid.2010.06.004

47. Agol VI. The 5'-untranslated region of picornaviral genomes. Adv Virus Res. 1991;40:103-80. http://dx.doi.org/10.1016/ S0065-3527(08)60278-X

48. Dockter J, Evans CF, Tishon A, Oldstone MB. Competitive selection in vivo by a cell for one variant over another: implications for RNA virus quasispecies in vivo. J Virol. 1996;70:1799-803.

49. McLinden JH, Kaufman TM, Xiang J, Chang Q, Klinzman D, Engel $\mathrm{AM}$, et al. Characterization of an immunodominant antigenic site on
GB virus $\mathrm{C}$ glycoprotein $\mathrm{E} 2$ that is involved in cell binding. J Virol. 2006;80:12131-40. http://dx.doi.org/10.1128/JVI.01206-06

50. Domingo E, Sheldon J, Perales C. Viral quasispecies evolution. Microbiol Mol Biol Rev. 2012;76:159-216. http://dx.doi. org/10.1128/MMBR.05023-11

Address for correspondence: Karol Perlejewski, Medical University of Warsaw, Department of Immunopathology of Infectious and Parasitic Diseases, 3C Pawińskiego St, 02-106 Warsaw, Poland; email: kperlejewski@wum.edu.pl

\section{April 2017: Emerging Viruses}

- Biologic Evidence Required for Zika Disease Enhancements by Dengue Antibodies

- Neurologic Complications of Influenza B Virus Infection in Adults, Romania

- Implementation and Initial Analysis of a Laboratory-Based Weekly Biosurveillance System, Provence-Alpes-Côte d'Azur, France

- Transmission of Hepatitis A Virus through Combined Liver-Small Intestine-Pancreas Transplantation

- Influence of Referral Pathway on Ebola Virus Disease Case-Fatality Rate and Effect of Survival Selection Bias

- Plasmodium malariae Prevalence and csp Gene Diversity, Kenya, 2014 and 2015
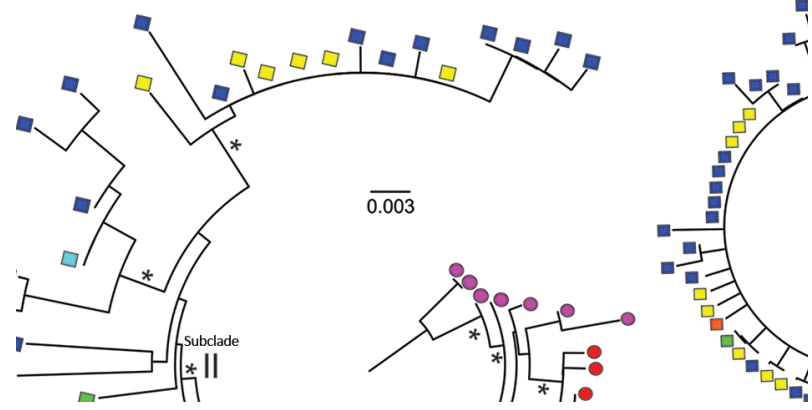

- Presence and Persistence of Zika Virus RNA in Semen, United Kingdom, 2016

- Three Divergent Subpopulations of the Malaria Parasite Plasmodium knowlesi

- Variation in Aedes aegypti Mosquito Competence for Zika Virus Transmission

- Outbreaks among Wild Birds and Domestic Poultry Caused by Reassorted Influenza A(H5N8) Clade 2.3.4.4 Viruses, Germany, 2016

- Highly Pathogenic Avian Influenza A(H5N8) Virus in Wild Migratory Birds, Qinghai Lake, China

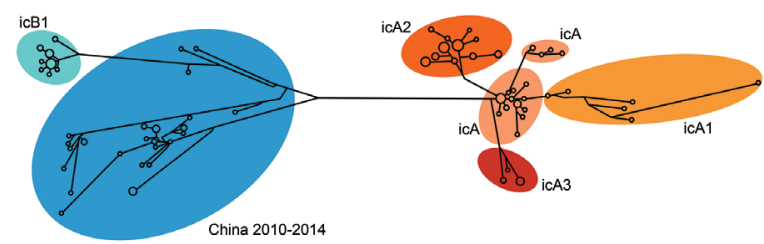

- Design Strategies for Efficient Arbovirus Surveillance

- Typhus Group Rickettsiosis, Texas, 2003-2013

- Detection and Molecular Characterization of Zoonotic Poxviruses Circulating in the Amazon Region of Colombia, 2014

- Reassortment of Influenza A Viruses in Wild Birds in Alaska before H5 Clade 2.3.4.4 Outbreaks

- Incidence and Characteristics of Scarlet Fever, South Korea, 2008-2015

- Markers of Disease Severity in Patients with Spanish Influenza in the Japanese Armed Forces, 1919-1920

- Molecular Identification of Spirometra erinaceieuropaei in Cases of Human Sparganosis, Hong Kong

- Zika Virus Seroprevalence, French Polynesia, 2014-2015

- Persistent Arthralgia Associated with Chikungunya Virus Outbreak, US Virgin Islands, December 2014February 2016

- Assessing Sensitivity and Specificity of Surveillance Case Definitions for Zika Virus Disease

- Detection of Zika Virus in Desiccated Mosquitoes by Real-Time Reverse Transcription PCR and Plaque Assay

- Surveillance and Testing for Middle East Respiratory Syndrome Coronavirus, Saudi Arabia, April 2015-February 2016

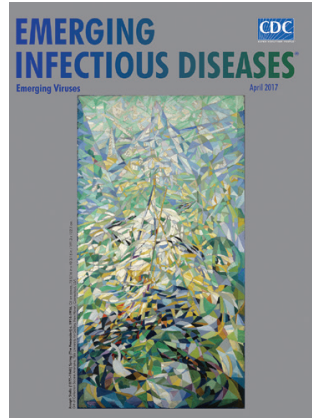

